\title{
THE DEVELOPMENT OF BULGARIAN ARCHITECTURE 2010-2020
}

\author{
TODOR BouleV \\ Union of Architects of Bulgaria, \\ 11, Krakra St., Sofia 1504, Bulgaria, \\ e-mail: boulev@abv.bg
}

\begin{abstract}
This paper aims at giving a general picture of the architectural processes in the last decade. Architecture is approached in broad terms - from spatial planning through architecture of buildings, architectural design and interior, problems of urban and landscape design. The European funds and the new environmental planning instruments (integrated plans and others) played an important role in this period, although great social inequalities in the development of regions and towns are still characteristic. New types of building complexes surfaced, such as the "mall", the "closed" residential estates and recreational complexes, the skyscrapers. There were many archeological sites restored, sometimes in debatable ways. The language of architecture became more similar to that of neotraditionalism and the quality of construction also developed significantly.

Keywords: regional and territorial planning, urban planning, urban design, architecture, closed complexes, heritage, regeneration, skyscraper, competition, Union of Architects in Bulgaria, Chamber of Architects in Bulgaria.
\end{abstract}

\section{INTRODUCTION}

This paper is a summary of the report, which was prepared following a decision of the Union of Architects in Bulgaria (UAB) Board, and provides an overview of the characterisation, analysis and evaluation of the architectural processes in our country over the past decade ${ }^{*}$.

A few words about the specifics of this paper: Its task is to stimulate and revive the discussion on the Bulgarian architecture in the UAB, especially about its current problems, by giving a more general picture of the processes

\footnotetext{
DOI: $10.7546 /$ EngSci.LVII.20.03.04

* The full text of the report, which naturally grew into a study of more than 100 pages, is published on the UAB website and printed as a separate booklet [1].
} 
within it. This proved to be a difficult task, mainly due to the scatterness and incompleteness of the information as well as because of the complete absence of primary analyses (excluding some publications on urban planning). This conclusion is mainly valid with a view of the last ten years, which determines the time frame of the paper.

The second important feature of this paper is approaching architecture in broad terms - from spatial planning, through architecture of buildings and complexes, to architectural design and interior. Thus, it includes problems of urban planning, urban environment, landscape and others. I believe that it is the UAB duty to place in front the architects and the society precisely this understanding, which is one of the starting points in the development of the twentieth century architectural modernism.

The third feature is hidden in the desire to objectively and critically characterise the participation of UAB in the architectural policies and the architectural processes. This participation, to share this immediately, is declining and unsatisfactory.

\section{STATE OF THE ART}

In 2007, Bulgaria was accepted as a full member of the European Union, which strengthened the process of synchronisation of the legislation and regulations with those of the European Union; however, we still cannot claim that the normative system regulating the development of the material living environment and the architecture, as a supporting element in this process, is fully developed (hence the criticism of the Spatial Development Act, the idea to develop a Law or an Architectural Code of Conduct). However, the European funds and the environmental management instruments (mainly the integrated plans) played a very important role during the period. The period is characterised by a relative stability in terms of political governance, which allowed the implementation, fully or partially, of a number of important infrastructural projects $[2,3,4]$.

In economic terms, the activities of economic entities have been diversified; the IT and the "outsourcing" sectors have developed rapidly. Despite the crisis of 2008-2009, there has been a relatively steady growth of the national wealth rates - Gross Domestic Product (GDP). Despite the manifestations of an oligarchic model in the distribution of income, the strata of a "higher" level of the middle classes was formed, and in general the increase of the living standard - as expressed in a developed object and market of new housing construction, increased motorisation, technicalisation and wide penetration of 
digital technologies in the home. The greater volume of state and municipal funding (mainly through the redistribution of European funds) is also not one of insignificance. However, the great territorial disparities in the direction of investments, the continuing demographic crisis, the desolation and depopulation of ever larger territories, the increasingly distinct social inequalities must be pointed out. While in some cases there are strong economic interests such as intensive construction (and redevelopment - for example in Sofia, on the Black Sea coast) in many places many of the existing buildings are abandoned and fated.

All this created relatively better conditions for practicing the architectural profession as compared to the previous periods (1990-2000 and 2000-2010) of the so-called "transition". Larger design companies appeared and the volume of architectural orders expanded. The Chamber of Architects in Bulgaria $(\mathrm{CAB})$ strengthened and asserted its positions (according to many colleagues, this is what causes a crisis within the UAB, but this is hardly the main reason).Compared to the times of "mutrobaroque", the number of investors with opportunities and more involved in a higher culture of design and construction has increased. Digital technologies have entered sustainably and, in general, with a positive effect in architectural design. During the explored period, we had great interest in the profession, in addition to UACEG, three other architectural faculties have been established. There was a temporary (in my opinion) problem with the "overproduction" of architects. But on the one hand, quite a few young colleagues went abroad; at the same time, on the other hand, we must take into account that the need for architectural services (not only design) is yet to only increase.

One of the important features of the 2010-2020 period is the restoration, in the first place, of the hierarchical system of developmental projects within a variety of scales - from national to local (municipal and city) level, and, secondly, the synchronisation between these plans and documents regulating social-political development. This was enshrined in the 2001 Spatial Development Act, and later in the Regional Development Act of 2008, and was stimulated by a number of European directives and sources of funding. But real products did not appear until later, in the last decade.

In 2011-2015, the National Conception for Spatial Development was developed, revised and finally adopted in 2020. It embodies the idea of moderate polycentrism and hierarchy of the settlement network, with leading centres Sofia, Plovdiv, Burgas, Varna and others. The territorial urban structure, developed together with the concept, strengthening the specific territorial structure of the landscape, with (relatively) extensive natural and protected areas. 


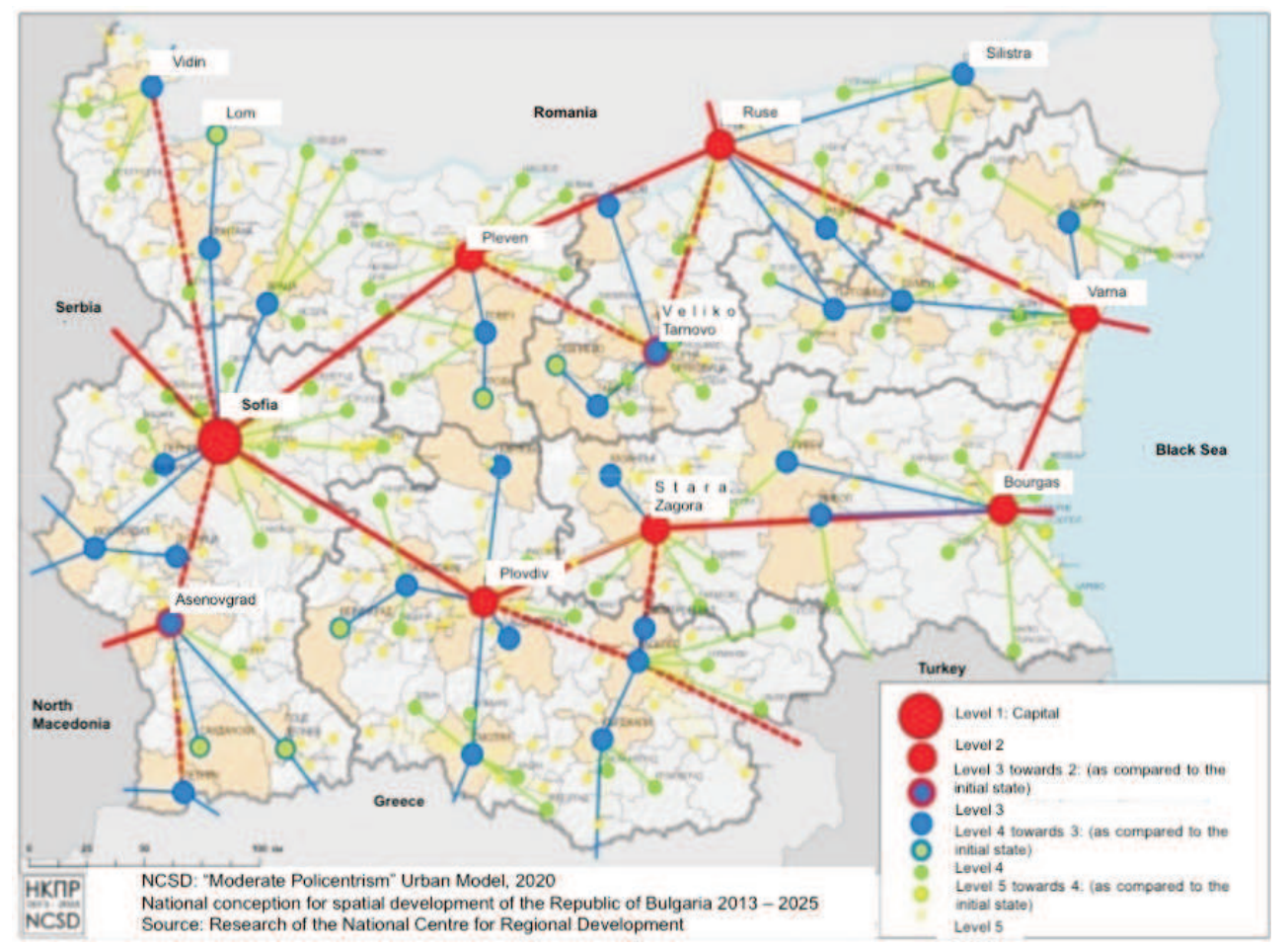

Fig. 1. National Concept for Spatial Development, 2020 "Moderate Polycentrism" Urban Model

Although the very appearance of these developments and the related spatial concepts for the regions are an achievement, the need for the still missing specialized "macro-development" projects for the Danube and Black Sea coast, for the urban axis "North - South" through VelikoTarnovo, Gabrovo and others. The national concept also offers us a radical approach to the problems of decentralisation of the economy and to the demographic problems, Figs 1 and 2.

Even though with a delay, the Ministry of Regional Development and Public Works has made commitments regarding a new type of tools for local spatial planning - General Settlement Plans of the Municipalities (GSPM), and currently for nearly 150 of the 265 municipalities we have plans adopted or in the process of adoption. However, the accelerated assignment of these developments also had its downsides - "replication" of a method that was incomplete in some respects, especially in terms of landscape design, where the GDP plays an important role in terms of the economy and demography of municipalities.

Engineering Sciences, LVII, 2020, No. 3 


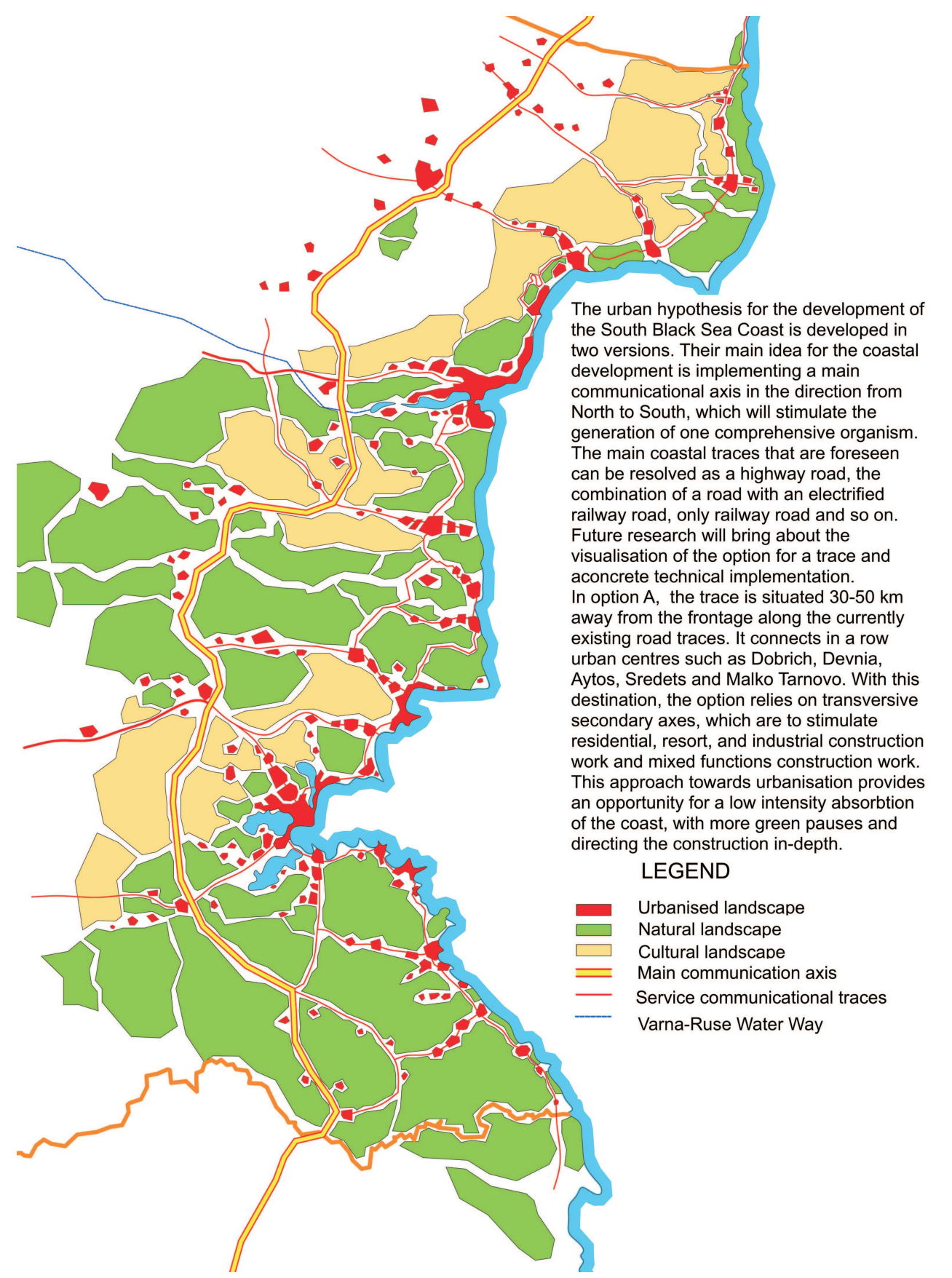

Fig. 2. Complex development scheme for sustainable development of recreation and landscape of the Bulgarian Black Sea coast, urban hypothesis, team of VFU "Ch. Hrabar" 
There is a tendency for political, not professional approach in the selection of designers, dumping in prices, often thwarted competitions under the Public Procurement Act. That is why we are promoting the idea of a national meeting - a discussion on the problems of the General Management Plan, together with National Association of the Municipalities in Bulgaria, the Ministry of Regional Development and Public Works, possibly the Ministry of Culture and the Ministry of Environment and Water. This meeting would also serve as a basis for the orientation of more architects to this important issue, in which our presence is not sufficient now.

GSPM, however, do not remove the need for urban planning - general and detailed design; they cannot cover the problems of the necessary structural changes in the settlements, especially in the large and medium-sized cities, centers of municipalities. But to what extent the developed GSP (successors of the General City Plans) plans of Sofia, Plovdiv, Varna, Burgas, Stara Zagora, Sliven, Veliko Tarnovo and others, solve these structural problems? As negative trends we should mention the mechanical expansion of the territories, especially along the entrance-exit highways, the insufficient relief of the inner cores from transport, the increased norms for construction (such as density and intensity), the lack of implementation tools especially for the public-private partnership. The excessive caution with regard to private property and the property border partly turns the GSP into huge regulation and construction plans. Their long-term, directive, directional character is lost. However, we must also point out the positive development in the content and decisions of the GSP in terms of the export of major communication routes, greater attention to environmental protection, ecology, cultural heritage. Unfortunately, the GSP has not yet taken over its functions in terms of spatial development of settlements, which is of great importance. Although territorial development and decentralisation of community centers and a gradual transition to mixed zoning and mutual infiltration of functions are at stake, these approaches are not sufficiently supported by the authorities, Fig. 3.

The Integrated Plans for Urban Regeneration and Development (IPURD) also had a positive effect as a new tool for the implementation of project ideas, but this is definitely an insufficient tool. Obviously, much more attention must be paid to the topic of the implementation of the provisions of the IPURD in order for them to become a sustainable component within the municipal policy.

The great importance of the Detailed Development Plans (DDPs) that are being developed should be emphasized here, both as a link with the GSP and as a connection with the investment intentions. We are talking about a detailed 


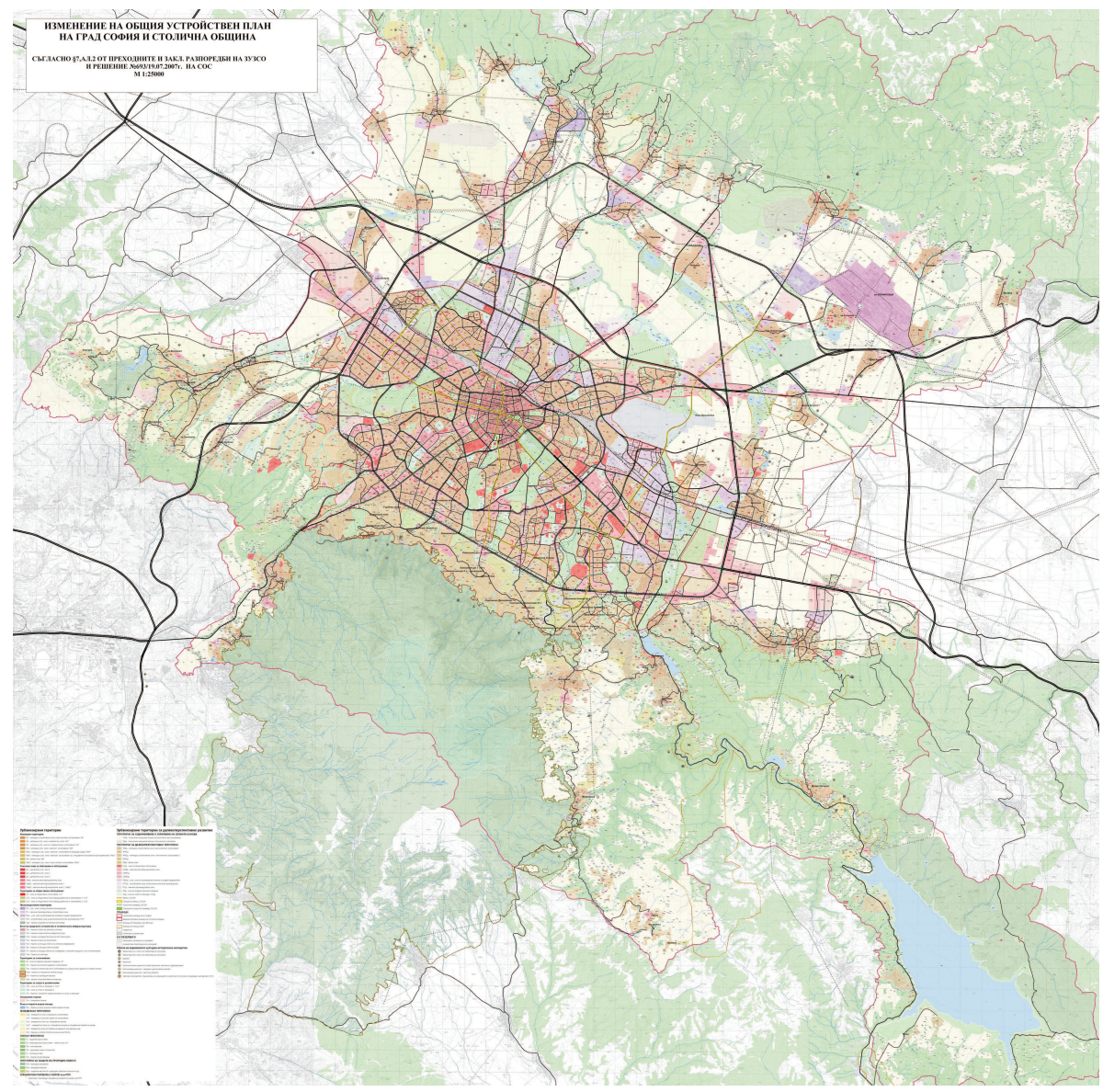

Fig. 3. A sample of the General development plan of Sofia municipality, OP "Sofproject - OGP"

urban plan, not about 2-3 properties that are casual, but about a detailed urban plan of urban structured parts with its own specifics and accompanied by individual rules and norms. Here we must also raise the issue of specialized DDPs for urban areas with a pronounced character and a specification for areas for regeneration and restructuring.

The theme of the urban environment and mainly of public spaces is a strong link between urban planning, architecture and the human being in the city. In the last ten years, many pedestrian areas, squares and individual streets have been designed or redesigned. Examples such as "Vitosha" Blvd in Sofia, "Aleksandrovski" Blvd and "Bogoridi" Blvd in Bourgas show that 
these solutions can have a very strong socio-economic effect, although they may have shortcomings in formal and design terms. We can point to Bourgas as an example of successful and multifaceted enrichment of the urban environment. Of a particular interest is the area for public access to the port, some elements of furnishing and more, Figs 4, 5 and 6 .

During the period under analysis here, some new architectural genres (housing estates and buildings) were developed and established - business and technology parks, intermodal terminals and logistics centres, large shopping and multifunctional centers (malls), large sports facilities, high-class office buildings, closed resort and residential estates, spa and spa hotels, guest houses. There were also quite a few proposals for "skyscrapers" with different purposes. The grouping of office buildings in specialized centres, located in the periphery, can have a strong city-forming effect "Business Park", Sofia. The complementarity of the shopping centres, the malls, with office structures, mutually reinforces both components, Fig. 7 .

The "malls" have provoked a number of contradictory assessments. This world practice could not pass us by and brought new practices and standards in the system of commercial services, in the city life, in interior architecture. However, it is becoming increasingly clear that they cannot replace such traditionally urban structural elements as the public square, the shopping street, the square. The compacted use of the terrain, the obligatory access with personal vehicles, the large volumes cause problems of their inclusion in the urban architectural and social environment.

These are undoubtedly complex and interesting, generally successfully mastered by their authors, architectural sites. However, the effectiveness of these investments is debatable, so the multi-functionality that is observed, for example, in Rousse (hotel, trade), Stara Zagora (trade, public halls) must be positively assessed.

The most common type of public facilities built in the last decade were indoor sports entertainment facilities with a capacity of 2-3000 up to 10-12000 visitors.

The residential architecture continues to be the most popular architectural practice; however, there is a lack of both a well-established housing policy and an evenly focused professional interest in the various problems of the housing environment and housing policy.

It is about preserving the qualities and partial regeneration of residential complexes; for the reconstruction and modernisation of the historically valuable building stock in the central cores; for the future of the numerous Roma neighbourhoods; for, albeit partial revival, of the villages, etc.

Engineering Sciences, LVII, 2020, No. 3 


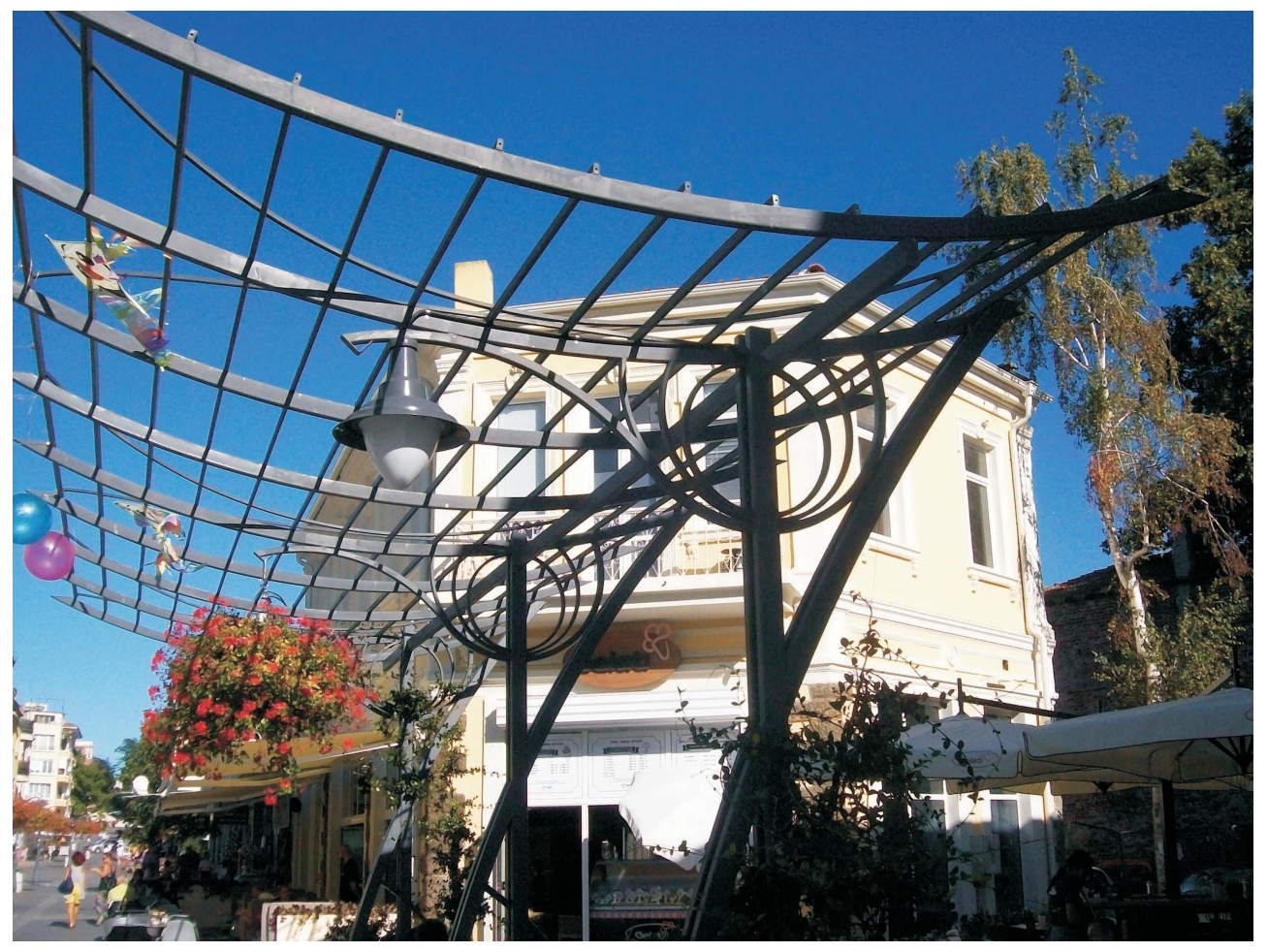

Fig. 4. Bourgas, "Aleko Bogoridi" Street

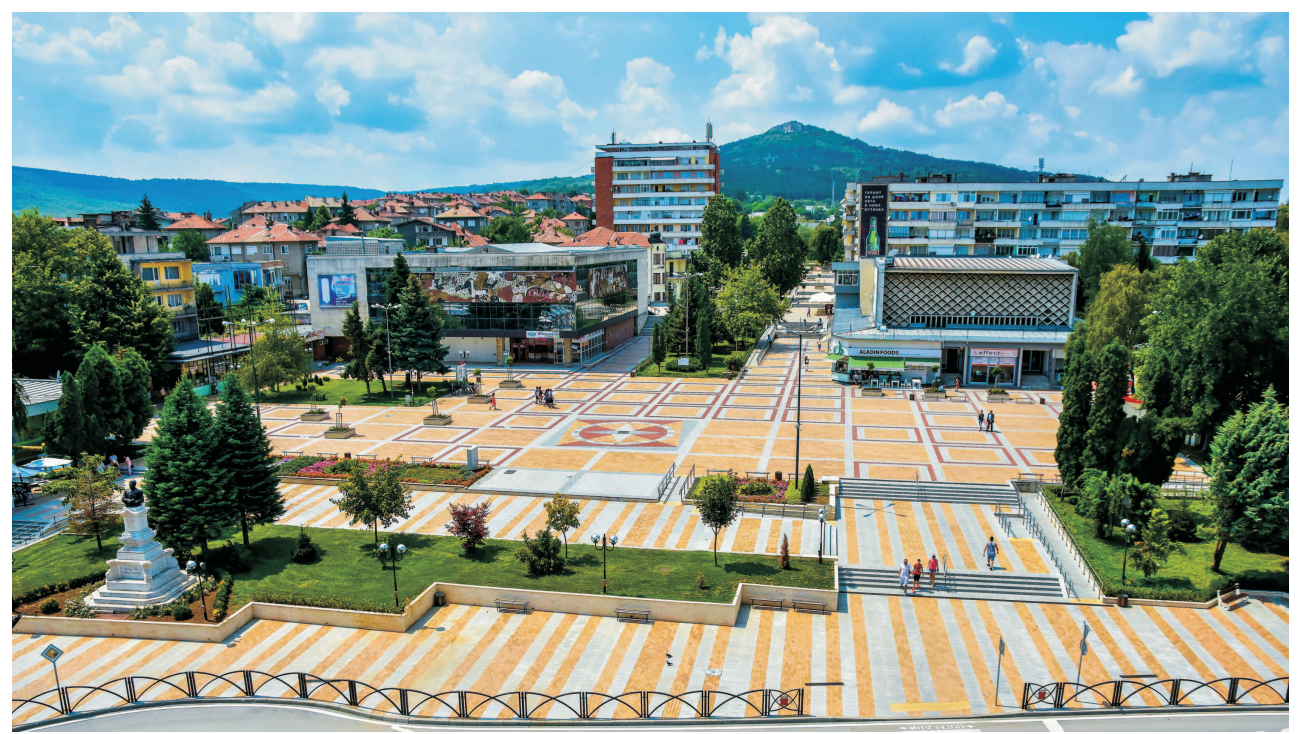

Fig. 5. Pedestrian Zone, Gorna Oryahovitsa, arch. Ira Kaneva 


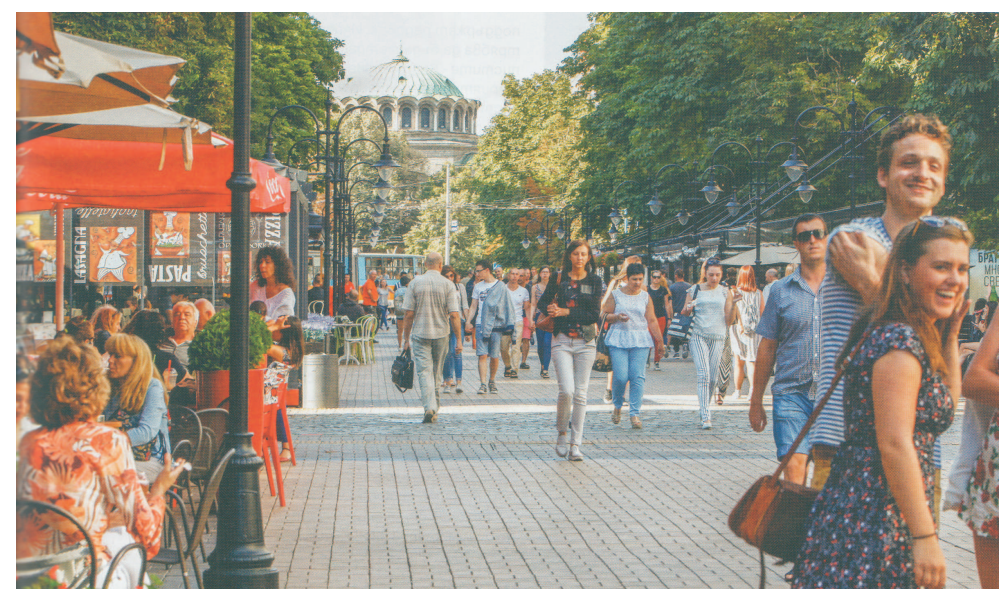

Fig. 6. Sofia, "Vitosha" Blvd, Pedestrian Zone, arch. T. Boulev, arch. A. Vatev and others

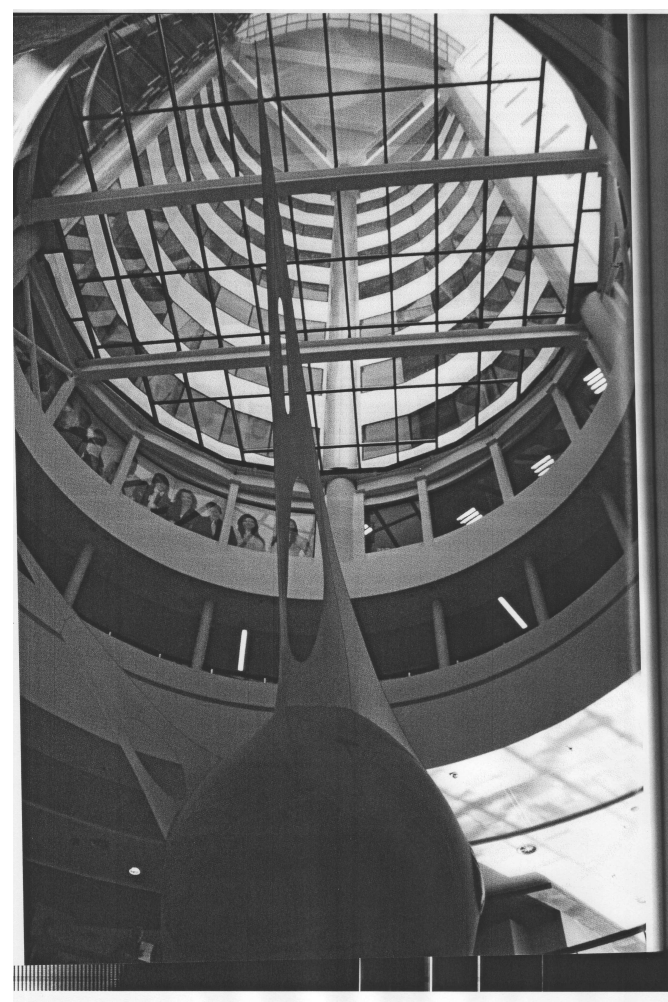

Fig. 7. "Varna Towers" Business Centre and Mall, arch. St. Mihaylov 
One of the sustainable trends in housing construction in recent years is the construction of relatively small (compared to those before) estates, but still fully designed housing structures - closed housing estates (the trend towards "closed estates" appeared even in previous times in resort and tourist development).

The very fact of complex and ensemble (as an idea) construction of larger "architectural units" of a separate building is positive. But the results are not always adequate to the intentions; in low-rise complexes there is excessive homogeneity, monotony; for medium- and high-rise buildings - overcrowding, lack of unity. The segregation of the inhabitants, which is caused by the closed complexes, is another markedly negative, social effect. The "mini-estates" remain not only closed but also isolated; they create their own microenvironment, but not the larger organism of the resort or city, Fig. 8.

One of the important architectural themes that has been rehabilitated attracts more professional interest and criticism to the legal framework and practice and to the modern life of the cultural heritage in the material environment. Globally, the search for large-scale regeneration of old buildings and neighbourhoods, for established principles of integrated conservation, expanded the protection of cultural landscapes, old industrial buildings, heightened the attention to the protection of modern architecture. These processes find only a partial response in our country. Many of our historical settlementsreserves (Melnik, Nessebar, Sozopol) have undergone both external changes and changes in their environment, which can be unconditionally considered negative. To an even greater extent, this applies to the neighborhoods with architectural heritage from the XIX-XX century in Sofia, Varna and others.

In this context, the UAB campaign for the protection of Bulgarian architectural modernism "White Paper", although belated, is emerging as necessary and as deserving support from both architects and the public.

The last decade has been characterized by an increased interest in the archaeological heritage, but also with much controversy surrounding the outcome of its exposure, the expression of the original substance and our right to upgrade and build on it (and to what extent?) to achieve a stronger (but and, as a rule, controversial) figurative suggestion. And here, the topic deserves a multi-layered discussion; it is not by accident that one of the next issues of the "Architecture" Journal will be devoted entirely to modern structural, architectural and social approaches to heritage, Fig. 9.

For more than 30 years, our architecture has evolved into socio-economic realities that are radically different from the previous, let us call it "socialist", period. In the complex conditions for expressing personal creative views at the 


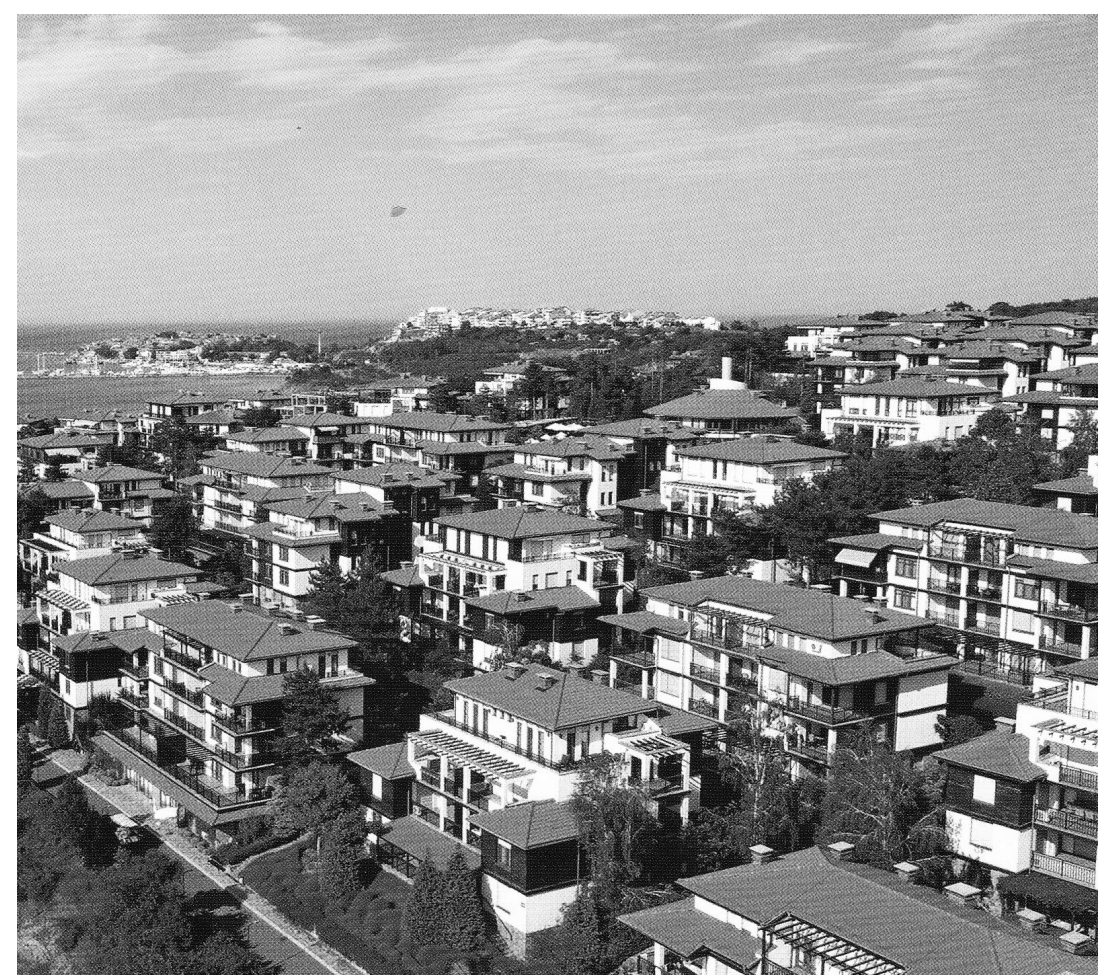

Fig. 8. Sozopol, "Santa Marina", Resort Residence Estate, "Petko Marinov and Co" Architectural Studio

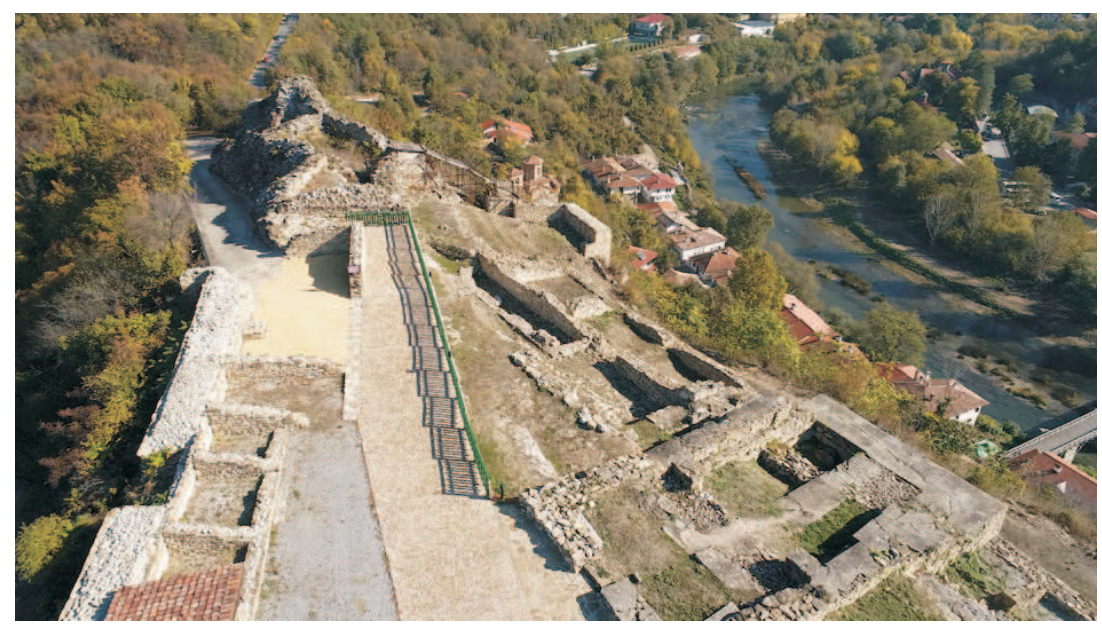

Fig. 9. "Trapezitsa" Hills, V. Tarnovo, restoration works, arch. Pl. Tsanev, arch. K. Totev 
time, the Bulgarian architects were able to protect the principles of modernism in their creativity and their empathy for the searches and development of world architecture, large personalities with prominent creative features and individuality appeared.

If in the preceding period we had to massively tolerate the restrictions imposed mainly by lack of construction capacities, financial resources and conceptual and political suggestively, then in the last thirty years we found ourselves entirely in the hands of newly coming investors, with different tastes and financial capabilities, but which, as a rule, wholly subjugated the architect to the level of a contractor of the holders of property, power and money. Together with the weakening of the role of UAB in society, with CAB still incomplete in its functions, an even more complex environment for architectural creativity was created. The affirmation of new names in architecture was inevitably related to receiving larger commissionings, and this, in turn, to an overly subordinate position in relation to the investor (the commissioner, the owner).

Therefore, in our architectural environment, the masses are still "architectschameleons", who are pragmatic and business oriented and ready to change their "style" according to the circumstances. This, by the way, is the case around the world, such architectural periods have existed in the past.

Nevertheless, we can argue that today the architect is better positioned as compared to 20-30 years ago, that there are already private investors and companies looking for and valuing the good architecture and the name of the architect, and that a number of architectural studios and names have emerged who protect their sustainable creative positions, as well as that buildings with a pronounced personality and imagery appear, which mark the modern stage of "pluralistic" modernism, in our current conditions. We can observe a stable tendency of soothing and a return to the roots of modernism, in the architectural language (as opposed to the belated "postmodernism" of the 1990s and the eccentric plastic ramblings from the border of the two millennia). This does not exclude another sustainable presence, more historically oriented solutions, of a more neoclassical or a national-romantic nature.

The buildings that attract attention, with their search for an architectural imagery, are not always large buildings; on the contrary, smaller objects (such as individual residential buildings) allow for more prominent and original artistic solutions. Overall, there is also a consistent uptake of newer and better quality materials and technologies. Although this in itself does not determine the architectural quality, it leads in general to the emergence of a new, specific architectural landscape. With no doubts, the most convincing sign of 
new technological opportunities is in the construction of very tall buildings "skyscrapers". The first finished, or started but unfinished, buildings of this type illustrate the much more complex problems associated with them, which are far from limited to technical opportunity and "prestige", Fig. 10.

The big problem with the development of our architecture remains, in my opinion, the protection of the principles of complexity, the role of space as an integrating substance, connectivity and ensemble, the contextualism in architectural solutions, the interaction between welded and new buildings, between new and more recent buildings. To consider these principles to be "socialist" or outdated is deeply wrong. On the contrary, we must defend the principle of contextualism (in the broad sense of the word) as necessarily complementarity and enrichment of the "individualism" of the single object.

\section{CONCLUSION}

To summarise this paper, I also want to mark some significant changes in recent years in the conditions for architectural creativity:

First of all, this is the much wider and more multi-plan application of digital technologies. In addition to the connection with Building Information Modelling (BIM) and a number of standards for sustainable architecture, they also allow "remote" creativity, the emergence of teams whose participants are in different countries and continents.

Secondly, at the same time our architectural practice is "internationalised". Our architects work abroad, but also foreign architectural bureaux enter our country, thus increasing competition, Fig. 11.

Thirdly, a gradual restructuring takes place; larger architectural offices have appeared, along with the architects "loners" ("samurai") and "family" bureaux. This process is natural and even belated, but it has yet to hint at problems and at new question marks.

Fourthly, state and municipal procurement continues to occupy an important place in the investment process and this, once again, raises the question of the practice of the PPA, which has been repeatedly criticized by us. Nevertheless, in recent years, we have also had a number of competitions with a pronounced architectural orientation - unfortunately, in them, as a rule, the UAB was not active enough.

Fifth, we observe the "ebb" of architects from a number of professional spheres, such as urban planning, landscape architecture, interior architecture, participation in architectural management and the construction process, and the liberated "niches" are quickly taken up by other related specialisations.

Engineering Sciences, LVII, 2020, No. 3 


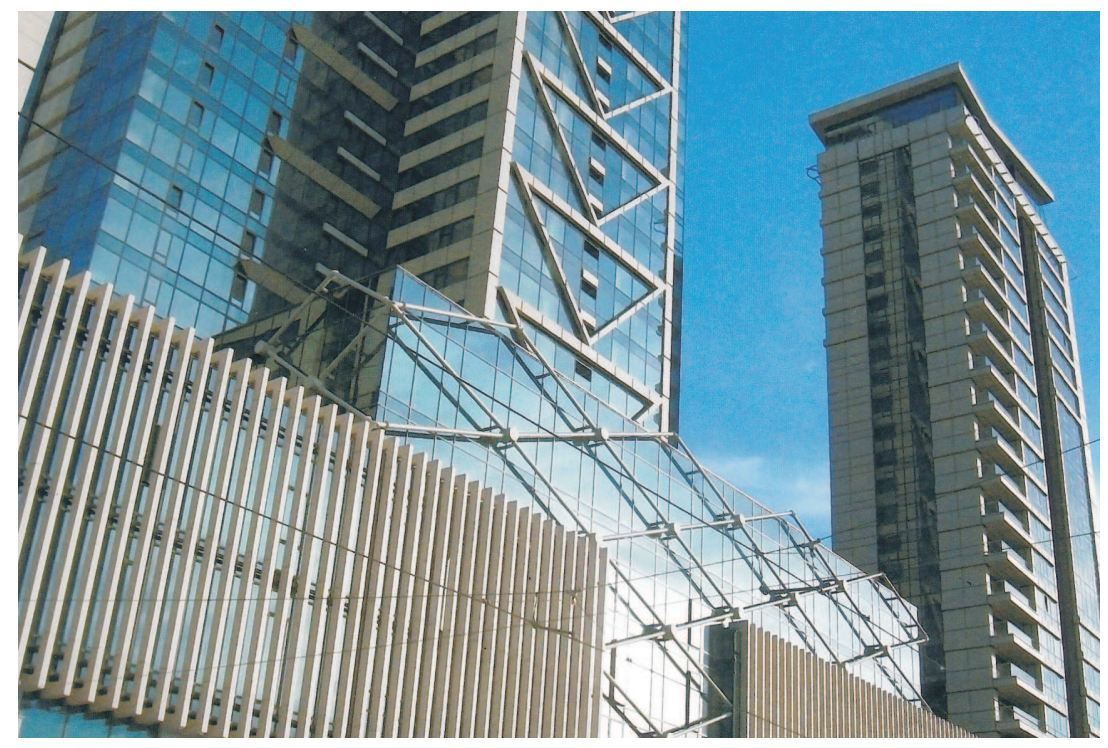

Fig. 10. Sofia, "Millenium Centre", "Amphion" Architectural Bureaux, arch. B. Bogdanov

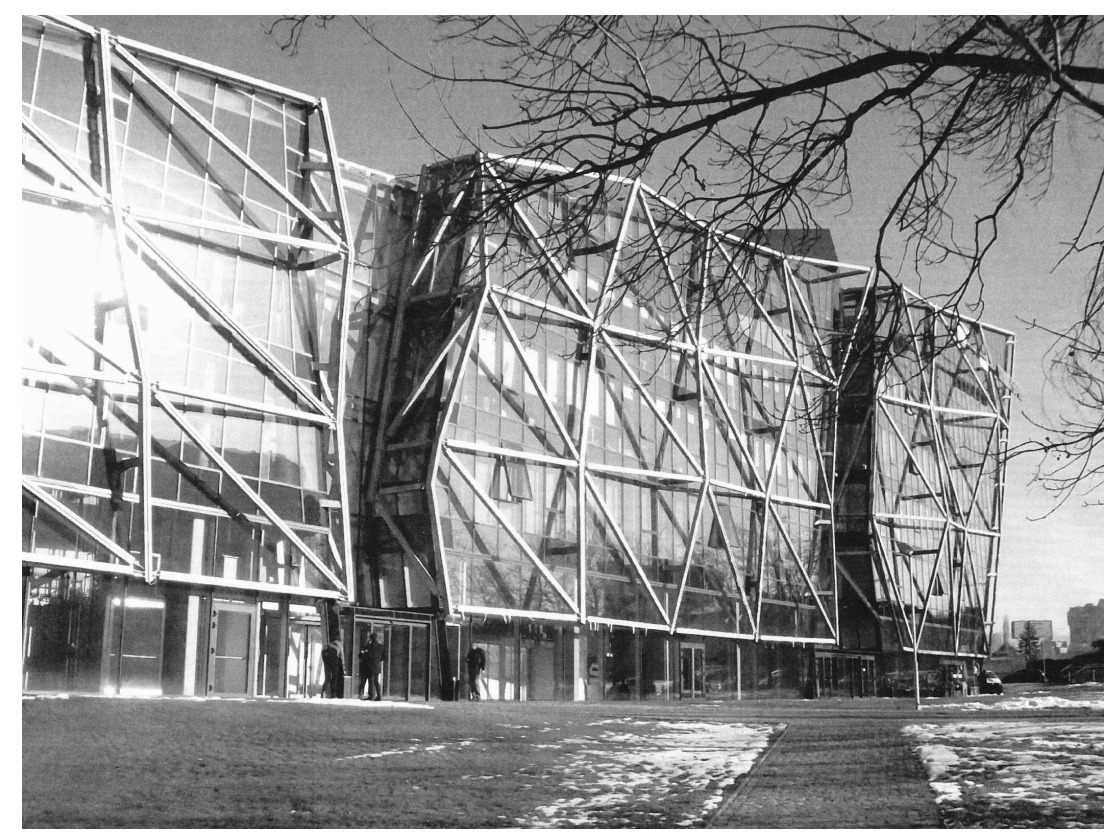

Fig. 11. Sofia, "Collider Activity Center", Architectural studios: Mars Architects + Intoarch 
Sixth, unfortunately, in recent years, architectural theory and evaluation practice have lost ground and barely manifest themselves. And that is exactly what we need, in the mosaic picture of modern times. I believe that the UAB should set itself the task of uniting the academic community (however conditional this concept may be now) and to revive the architectural science.

\section{REFERENCES}

[1] Todor Boulev, Bulgarian Architecture in the Period 2010-2020, UAB, Sofia (2020).

[2] Ivan Nikiforov and Mila Nikiforova, Urban Planning in Bulgaria in the XX-XXI Century, Slavena, Varna (2019).

[3] Elke Beyer, Annhegeman, and Michael Zinganel, Holidays after the Fall, Jovis Verlag GmbH (2013).

[4] Adolph Stiller, Architektonishe Fragmente Bulgarien, Verlag Anton Pustet, Vienna (2010).

Received September 28, 2020

Engineering Sciences, LVII, 2020, No. 3 